\title{
SCIENCE, RELIGION AND COMMON SENSE
}

\author{
LOUIS CARUANA \\ Heythrop College, University of London
}

\begin{abstract}
Susan Haack has recently attempted to discredit religion by showing that science is an extended and enhanced version of common sense while religion is not. I argue that Haack's account is misguided not because science is not an extended version of common sense, as she says. It is misguided because she assumes a very restricted, and thus inadequate, account of common sense. After reviewing several more realistic models of common sense, I conclude that common sense is rich enough to allow various kinds of extensions. Just as science can be correctly seen as an enhanced version of common sense, so also religion.
\end{abstract}

These last decades, the vast literary output on science and religion has concentrated on cutting-edge developments in science, mainly in theoretical physics, cognitive science, and evolutionary biology. Philosophy of religion in this area has therefore struggled with various intricate arguments that are often heavily interlaced with the technical language of these sciences. Against this background, a new kind of argument is now emerging, a form of argument that cuts across these well-established debates because it refers not to scientific discoveries but to the rather mundane idea of common sense. If science is an elaborate, extended, or enhanced version of common sense, while religion is not, can we conclude that science is better than religion? An answer to this question has crucial repercussions in a number of areas of philosophy. For instance, it would throw light on the impact of a new form of naturalism that is gaining popularity, a form of naturalism less associated with positivism and more with pragmatism. It also would redraw attention to the philosophical centrality of common sense as a possible source of justification. 
Hence it is timely to deal directly with this question, and a good way to situate the discussion is to start with Susan Haack's book Defending Science Within Reason, where she articulates this issue very clearly. I will first give an overview of her main arguments, especially those that deal with religion, and then will proceed with a sustained analysis of the nature of common sense and of its alleged role in justifying science and discrediting religion.

\section{SUSAN HAACK'S POSITION}

Haack's overall view of scientific inquiry is pragmatic. She explains her agenda early on in the book as one of articulating a healthy middle way between two opposed extreme views. She calls these two views the Old Deferentialism and the New Cynicism. Old Deferentialism is the position according to which science progresses mainly inductively by accumulating true or probably true theories confirmed by evidence. This procedure of science, and variations of it, have been clarified by logical analysis and defended against a number of logical paradoxes that have been wedged against it these last decades. The overall impact of this position is over-optimism, a kind of scientism. The other position, the New Cynicism, is diametrically opposed to this. Blatantly anti-scientific in tone, this New Cynicism rejects the value of inquiry. It endorses relativism, and sometimes even tries to accomplish the logically impossible: it tries to talk intelligently about the rejection of all rationality. Susan Haack stays clear of both these positions and seeks the middle ground because she thinks that both positions not only are extreme positions but also suffer from the same deficiency. They both suffer from a lack of serious engagement with the world. They both are incapable of explaining how through science we can affect the world and be affected by the world. What she means here is explained by the use of an analogy: the analogy of a crossword puzzle. Scientific practice, including evidence and method, is very similar to the entering of words in a crossword puzzle, the entering of the correct words and not just any words, entering words that intersect with others already written, words that are partially supported by previous entries, and words that are themselves partial support for future entries. She calls her middle way critical common-sensim, a term she draws from Charles S. Pierce. 
Following the lead of many prominent scientists, she holds that science is the long arm of common sense. ${ }^{1}$ By this, she means that scientists are not employing some special method of inquiry unavailable to non-scientists. Science is a refinement of everyday thinking. In line with this, she adopts a direct form of realism. She holds that there is one correct description of the world, whether we know it or not, and that the scientific method is our way of discovering more and more details about this correct description. In all this, she remains modest. She acknowledges not only the achievements of science, but also 'the pervasive fallibility, the imperfections and flaws, the sheer untidiness, of this remarkable but thoroughly human enterprise' (Haack 2007: 123). Once she establishes in this way the general features of her overall approach, she proceeds by discussing various peripheral issues related to science, such as the strengths and weaknesses of sociological studies of science, and the tension between scientific and literary cultures. In all this, her position is similar to that of C. S. Pierce.

As regards the specific area of religion, which is our main interest in this paper, she starts by recalling the considerable differences that exist between science and religion. They not only have very different conceptions of the universe; they even have very different views on what constitutes a good explanation. One the one hand, there is science, which has developed ways of extending the power of our senses and ways of enhancing our faculties of reasoning, remembering, and calculating. Science does all this by carefully eschewing appeals to supernatural forces and by resorting only to empirical evidence. And on the other hand, there is religion, which, according to Haack, is not primarily a kind of inquiry at all, but a creed built around one core idea, the idea that 'a purposeful spiritual being brought the universe into existence, and gave human beings a very special place. This spiritual being is concerned about how we humans behave and what we believe, and can be influenced by our prayers and rituals' (Haack 2007: 267). Admittedly, theology, as a rational expression of religion, is indeed a form of inquiry, but, like religion, it differs radically from scientific inquiry because it welcomes explanations that involve supernatural features. One needs to note at this point that, when Haack is expressing this difference between science and theology, she does not do so in terms of how these two disciplines

${ }^{1}$ She refers, for instance, to Albert Einstein who held that 'the whole of science is nothing more than a refinement of everyday thinking' (Einstein 1934-1954: 290). 
function, but in terms of how they relate to everyday empirical inquiry. She writes: 'unlike scientific inquiry, theological inquiry is discontinuous with everyday empirical inquiry, both in the kinds of explanations in which it traffics and in the kinds of evidential support on which it calls' (Haack 2007: 267). The effect of this discontinuity is evident in the way theology, in the course of history, retreated at the same rate as science advanced. In Haack's way of putting it, theology retreated to 'higher ground'. By this, she means that theology kept readjusting its claims and diminishing their content until little or nothing factual is now left.

She turns then to address the debate between creationism and intelligent design theory. Protagonists on both sides of this debate think that there is no compatibility whatsoever between science and theology. She does not spend much time with Biblical literalists. She turns her attention to those scientists who defend religion by allegedly proving that evolutionary explanation is incomplete. Such a defence usually refers to parts of the organism, such as the eye or the DNA molecule, which are considered too internally complex to be producible in stages through natural selection. The argument, in short, is that, since evolutionary changes, by definition, occur only when they confer some survival advantage, and since the internal relations between the parts of such complex units are mutually dependent for the efficiency of the whole, a change in one of these parts can never result in conferring a survival advantage to the organism as a whole. This means that an evolutionary explanation cannot be correct for such cases. The parts must change all together for any survival advantage to be possible. And postulating a synchronized change of a group of variables all together goes against the idea of random mutations, which is a basic feature of any evolutionary explanation. Haack's refutation of this argument is interesting. Instead of entering into the intricate details of such arguments, as many others on both sides of the debate have done, she highlights the virtues of scientists. She concedes that there is no clear answer yet, and then describes how the occasional gaps in scientific explanation do nothing to diminish the determination of scientists, who are perfectly capable of admitting that some given question is not answered yet, and that they are therefore still working on it - the most natural way to proceed in such matters. Theologians are totally different. They can only reiterate: 'It was God who did it.' But this is not an explanation. It is a mere admittance of ignorance. It is just acknowledging that the explanation will remain forever inaccessible. For Haack, this attitude is very cheap; 
it is no substitute for the scientist's determination to dig further and further. She therefore feels perfectly entitled to reiterate her basic insight: 'supernatural explanations are as alien to detective work and history or to our everyday explanations of spoiled food or delayed buses as they are to physics and biology' (Haack 2007: 279). At this point, a religious believer may want to press the objection that religion is not as alien to human living as this quotation is implying. Religion is as deeply rooted in the history of humanity as any of these simple explanations that Haack is referring to, and has certainly deeper roots in history than science as we know it. To this possible objection, Haack's answer is typically pragmatic. She admits that, because of the ubiquity of religion within human society since earliest times, we need to concede that there must be something in it. She thinks however that, at this day and age when science has progressed so much, people must choose between science and religion - and her choice is clear: 'Religion is no less quintessentially human an enterprise than science; it is much older, and its roots in our psychological makeup perhaps deeper. But its fundamental appeal is to the side of the human creature that craves certainty, likes to be elevated by mysteries, dislikes disagreeable truths, and clings to the flattering idea that we are not just remarkable animals, but the chosen creatures' (Haack 2007: 293).

By now, Haack's overall attitude towards religion should be clear. For her, science is a respectable, extended version of common sense while religion is not. The solid grounding of science on common sense is what science has and what religion lacks as regards justification. Undoubtedly, the crucial factor in her argument is common sense. But what is common sense? Can it really offer Haack the leverage she needs to sideline religion?

\section{COMMON SENSE}

As a first approximation, we can start with the idea that common sense is the set of rational features common to all human beings. The basic idea behind this preliminary definition is that the word 'sense' within the expression 'common sense' is associated not with the concept of perception but with the concept of reasonability. The principles of common sense understood in this way can be manifested in the way people reason things out in normal circumstances. To make a list of these principles in detail is not at all straightforward. Consequently, although many people agree that it is perfectly correct to talk about common 
sense and even that the expression 'common sense' refers to something, not many would be capable of articulating even the major principles it consists in. Some prominent philosophers have had a go at this task, because they were motivated by the conviction that a lot of what we do in our intellectual activity depends on common sense. The result however has never been a complete list of principles. Aristotle and Thomas Reid, for instance, assumed the existence of common understanding, and they even considered it something like a platform on which elaborate philosophical arguments can be built. ${ }^{2}$ They went so far as to consider it a foundational source from which conclusions can be drawn about what can be said and what cannot be said, what can be deduced and what cannot be deduced. In the words of Thomas Reid, philosophy 'has no other root but the principles of Common Sense; it grows out of them and draws its nourishment from them. Severed from this root, its honours wither, its sap is dried up, it dies and rots' (Reid 1983: 7). These philosophers did all this however without ever coming close to producing a full list of constitutive principles of common sense. Some may think that this verges on the irresponsible. How can a philosophy be sound if it is based on common sense when the nature of common sense is not clarified first? Although this is an important question, it is not directly related to my aims in this paper. Suffice it to say that I do not think there is any major fault here. The basic assumption is simple. These philosophers, and others like them, assume that common sense includes foundational principles that are universally held and are consequently inviolable and unavoidable. Denying these principles would be selfcontradictory, either because these principles can only be denied in artificially construed contexts, far from any real life situation, or because these principles are always being assumed tacitly in the very process of denying them. ${ }^{3}$

${ }^{2}$ When we are discussing Aristotle, the expression 'common sense' can lead to ambiguity. He often uses the expression 'common sense' to refer to that mental faculty that brings to unity what is perceived in different ways by the different senses. What we nowadays refer to by 'common sense' is not this. For us, 'common sense' refers to those aspects of rationality that are common to all, for instance the principle of noncontradiction. Having said this, however, it is good to recall that this relatively modern use of the expression 'common sense' is also present in Aristotle, even though he does not refer to it by that expression.

${ }^{3}$ Useful explorations of the interface between common sense and science include: Gavin 1984, Musgrave 1993, and Rescher 2005. For a more general epistemological account, see Moore 1959, Chisholm 1977, Chisholm 1982, and Lemos 2004. 
For the argument I am focusing on in this paper, the main interest is the understanding of common sense by contemporary philosophers like Susan Haack. The way she appeals to common sense is typical of the philosophical tradition she belongs to, namely pragmatism. A typical pragmatist like Charles Sanders Peirce assumes that 'there are indubitable beliefs which vary a little and but a little under varying circumstances and in distant ages; that they partake of the nature of instincts [...] they are very vague indeed (such as, that fire burns)' (Peirce 1931-1958: 498). Peirce adds that these vague beliefs, which are constitutive of common sense, 'have the same sort of basis as scientific results have. That is to say, they rest on experience - on the total everyday experience of many generations of multitudinous populations [...] all science, without being aware of it, virtually supposes the truth of the vague results of uncontrolled thought upon such experiences' (Peirce 1931-1958: 522). ${ }^{4}$ The basic idea here is that human beings are all endowed with the elements of common sense and that they express these by vague propositions like 'fire burns'. Through the use of sophisticated scientific methods, such propositions are not falsified but refined. They are stripped of their vagueness, and thereby clarified. For Peirce and his followers, therefore, the continuity between common sense and science is clear and fundamental. And Haack is building her argument precisely on this continuity. For her, science is an enhanced version of common sense as described by Peirce. ${ }^{5}$

But now we have to face the crucial issue. Is common sense correctly exemplified by the belief that fire burns? In other words, is common sense limited to explanation of physical effects in terms of physical causes? Can people appeal to common sense when dealing with issues that go beyond the empirically verifiable? These questions are very important for Haack. She is arguing that there is continuity between science and common sense, and that this continuity justifies science as a legitimate mode of intellectual activity. Science is acceptable, she claims, because it is the long arm of common sense. Anyone who attempts to discredit science

\footnotetext{
${ }^{4}$ For further insight into Peirce's views, see his two papers 'Pragmaticism and Critical Common-Sensism'; and 'Consequences of Critical Common-Sensism' (both in Peirce 1931-1958, vol, 5). I discuss these issues in Caruana 2000, chapter 8.

${ }^{5}$ It is good to indicate here that Haack does not follow Peirce all the way. She seems to think that if one is a pragmatist one is obliged to be a religious unbeliever. Peirce himself, however, defended religious belief in his own way. The climax of his philosophy of religion is probably his 1908 paper 'A Neglected Argument for the Reality of God' (Peirce 1931-1958, vol. 6).
} 
will be discrediting common sense, and thereby sliding into irrationality. But could it be that common sense is a broader platform than she thinks? If it is, the justification she thinks is reserved only for science may in fact be available also for other modes of intellectual activity.

So my main contention with Haack should now be clear. I want to argue first that common sense is broader than instrumental reasoning, and secondly that, because of this, religion is justified as an enhanced version of common sense just like science.

\section{MULTIDIMENSIONAL COMMON SENSE}

The first step is to ask: how can common sense be broader than instrumental reasoning? To explore some possibilities, let us start with an example. Consider Aristotle's two famous claims: that all people desire to know, and that all people are driven by wonder. Such claims indicate that, for Aristotle, a person who does not desire to know, or who is not driven by wonder, would be lacking in something that is fundamental, lacking in something that is common to all humans. Of course, there are many features that humans share in common, such as having one heart and two lungs. But the features Aristotle is referring to in this context are not biological features; they are mental. A person who does not desire to know or who is not driven by wonder would be lacking in what pertains to the rational or to the conceptual dimension of being human in just the same way as an individual whose reasoning violates the principle of non-contradiction. Consequently, if I am reading Aristotle correctly, we have here an indication that there is more to common sense, understood as common rationality, than just principles that are embedded within explanation in terms of cause and effect. ${ }^{6}$

To explore this further, consider the set of concepts indispensable for inter-personal relations. These concepts are associated directly with the conceiving of other humans as persons: they are associated directly with the conceiving of others as irreducible units that are bearers of a specific

${ }^{6}$ I pick Aristotle as an example because of his particular affinity with today's scientific attitudes, an affinity that can best be seen in his method. He does not begin with being sceptical. He trusts our perceptual and cognitive faculties, and assumes that they put us in direct contact with reality. Starting from experience, he reflects deeply on any puzzles that such experience presents. And yet he does not limit his reflection to any one area of human activity. For him, what humans do by nature is broader than the science of production (see Metaphysica, 982b: 11-27). 
group of predicates, predicates associated with love, hate, sympathy, resentment, trust, suspicion, forgiveness, revenge, honesty, hypocrisy, and with other concepts like these. These concepts can function only once the concept of person, as a basic category, is in place. Can we consider this set of concepts dispensable? We cannot. Anyone who tries to live without them would simply drift away from the community that makes meaning possible. Moreover, any attempt to discredit the centrality of these concepts involves an instance of using them - because the very discrediting has to be carried out within a community of persons. Language itself is a communal activity. It is therefore clear that, if common sense is taken to be the set of all that is universally held and that is inviolable and unavoidable, it includes more than just the principles involved in instrumental reasoning in terms of cause and effect. Haack's argument is one-sided because she emphasizes only one dimension of common sense, and thinks that that is all there is to say about common sense.

My second step now is to show that just as science is an enhanced version of the instrumental dimension of common sense (which is just one of the many dimensions of common sense) so also religion is an enhanced version of another dimension of common sense, more specifically an enhanced version of the dimension that involves concepts associated with interpersonal relations. My argument here starts with a couple of observations concerning Haack's reasoning. What is it that convinces pragmatic philosophers like Haack that science can legitimately be called an enhanced version of common sense? First, I would guess, such people are impressed by the fact that the logical form of explanation within science is also found in common sense. It does not require much thought and self-reflection to realise that common sense involves observation, inductive generalizations (most of which are tentative), falsifiability tests, inference to the best explanation, and so on. All these features constitute the engine of sophisticated scientific research. Moreover, philosophers like Haack are also impressed by the fact that science generates the building of instruments that enlarge the range of observation, increase the speed of seeing correlations, and enhance other such operations. Such enhancement is essentially equivalent to enlarging the range of the simple explanations of everyday life.

Now consider religion. The list of basic concepts at work within a religious way of life includes not only the central concept of maximal greatness or infinite perfection, which is usually expressed by the word 'God'. It includes also concepts related to acting rightly and acting wrongly, 
to attributing praiseworthiness and blameworthiness, to honesty and hypocrisy, to love and hate, to consolation and desolation, to wonder and fear - all these basic concepts are the same in essence as those constituting the dimension of common sense associated with inter-personal relations. We may even add here that in some religious traditions, most notably in Christianity, even the concept of maximal greatness is associated with inter-personal relations. And this fact explains why even children can already have a basic sense of religion, a very simple but genuine sense of religion, from an early age. Moreover, religion is expressed through practices and rituals, both personal and communal, which enlarge or deepen the understanding of the interpersonal relations of everyday life. The sense of personal commitment and fidelity is highlighted, community ideals of goodness and beauty are deepened, global fraternity and personal self-giving are enhanced, ideals concerning loyalty and self-sacrifice are purified.

So the parallelism should now be noticeable. What justifies the idea that science is an enhanced version of common sense justifies also the idea that religion is, in its own way, an enhanced version of common sense as well. Common sense is rich enough to allow various genuine extended and enhanced versions of it. Science enhances common sense in one direction while religion enhances common sense in another direction. Science and religion are not competing extensions of common sense, but extensions of different dimensions of common sense. Science is an extension of the instrumental and explanatory dimension. Religion is an extension of the dimension of common sense that is associated with inter-personal relations.

One might object here that I am naïvely taking religion to be a force for the good. I seem to be arguing that religion enhances inter-personal relations in the sense of making them better. But if we think of the adverse effects religion has had on civilization in the course of history, we will never be tempted to see it as enhancement at all. This objection introduces an important point. Religion emerges within human culture in various ways, and not all these ways are positive. But this fact does nothing to undermine the main line of argument. Concepts associated with interpersonal-relations come in various kinds. If there is love, there is also hate; if there is honesty, there is also hypocrisy. Religion can enhance both the good ways we relate to each other and also the bad ways. And, within the major religions, this ambivalence is well recognized. It is dealt with 
by self-corrective mechanisms inscribed within their moral traditions. Notice that we can argue in a parallel fashion about science. Although it is agreed that science is an enhanced version of common sense, as defended by Haack, we cannot thereby deduce that science has always been a force for the good. We cannot thereby argue that science has been, and will always be, beneficial for genuine human flourishing. Being based on common sense is no guarantee that things cannot go wrong.

Some may want to object that my line of argument has stretched Haack's understanding of common sense beyond all recognition. She is talking about a set of common rules for inquiry, while I am talking about the set of concepts and presuppositions that are necessary for what might be called successful navigation through life. I concede that this is a legitimate observation, but I add that the distinction between the two accounts is not a weakness in my overall argument. The two accounts are intimately related. Since I am ready to accept that navigation through life, as understood here, is indeed helped by correct strategies of inquiry, my understanding of common sense is broader than Haack's and includes it. What justifies the broader view is the fact that human beings are not characterised only by skills regarding inquiry. They are characterised also by other species-specific dimensions of their activity, including all that is semantic, symbolic, personal, and interpersonal. These dimensions are as foundational a fact of human natural history as the fact that humans reason things out deductively and inductively, and have twenty-three pairs of chromosomes.

In highlighting this fact, I am in fact presenting an argument that is in line with an important trend in current biological thinking, a trend associated with the idea of the extended phenotype. The expression 'extended phenotype' is used by those who claim that considering an organism solely in terms of its constitutive microphysical and chemical processes is seriously limited. The basic proposal is that the phenotype of an organism, in other words its characteristic outward, physical appearance as distinct from its genetic makeup, is not limited to biological processes only; it should include also all the effects that that genetic makeup has on the environment. In other words, we need to accept that the specificity of any organism, when correctly understood, extends way beyond the individual microstructure and even beyond its surface features. For instance, we need to realise that the way beavers build their nest is as much part of the nature of beavers as the colour 
of their fur, the flatness of their tail, and the structure of their DNA. ${ }^{7}$ My broad view of common sense is similar to this. It is an extension of Haack's view just as the idea of the extended phenotype is an extension of the previous limited view of phenotype. In other words, I am urging that, to obtain a correct view of the specific rational nature of human beings, we cannot limit our considerations to how humans deal with simple inquiry of the form 'Why $P$ ?'. We need to broaden our range of vision, as it were, and acknowledge also how humans have an important speciesspecific side to their nature that arises from their complex symbolic way of relating interpersonally, from their appreciation of time, value, and personal commitment, and from the way in which they do not just exist but are infinitely interested in existing (Kierkegaard 1992: 302).

So to conclude, the main question addressed to Haack was this: can common sense be an efficient tool to justify science and discredit religion? I argued that the answer is no. The answer is no not because there is no such thing as common sense, and not because Haack has given a wrong characterisation of common sense. The answer is no basically because common sense is much broader than what Haack thinks it is. Of course, more work needs to be done. Perhaps there are objections I have not considered. Perhaps some would say that, as regards this issue, Haack's work is not a good place to start. And perhaps there is some argument that shows that religious activity is not in fact related to interpersonal relations after all. Given the strength of the pragmatist tradition, and the impressive philosophical skills of many within that tradition, it seems reasonable to predict that my argument will not convince everyone. Still, it remains to be seen why not. At the very least, I hope to have shown that those who adopt Haack's nuanced naturalistic approach to religion run the risk of ending up with a severely skewed view of what common sense can and cannot support.

\section{BIBLIOGRAPHY}

Aristotle. 1941. Metaphysica, trans. W. D. Ross, in The Basic Works of Aristotle, ed. R. McKeon (New York: Random House), pp. 681-926

Caruana, Louis. 2000. Holism and the Understanding of Science (Aldershot, U.K.: Ashgate)

${ }^{7}$ The idea of extended phenotype was popularized by Richard Dawkins (e.g. Dawkins 1999). Here I am referring to the basic features of this idea only. I am not endorsing his controversial view that genes are the fundamental units of evolutionary selection. 
Chisholm, Roderick M. 1977. Theory of Knowledge 2nd ed. (Englewook Cliffs, N.J.: Prentice Hall, Inc.)

Chisholm, Roderick M. 1982. The Foundations of Knowledge (Minneapolis: The University of Minneapolis Press)

Dawkins, Richard. 1999. The Extended Phenotype (Oxford: Oxford University Press)

Einstein, Albert. 1934-1954. 'Physics and Reality', in Ideas and Opinions of Albert Einstein, trans. S. Bargmann (New York, Crown Publishers), pp. 290-323

Gavin, William J. 1984. 'The "Will to Believe" in Science and Religion', International Journal for Philosophy of Religion, 15: 139-148

Haack, Susan. 2007. Defending Science Within Reason: Between Scientism and Cynicism (New York: Prometheus Books)

Kierkegaard, Søren. 1992. Concluding Unscientific Postscript to Philosophical Fragments, vol. 1, Text, ed. and trans. H. V. Hong \& E. H. Hong (Princeton, NJ: Princeton University Press)

Lemos, Noah. 2004. Common Sense: A Contemporary Defense (Cambridge: Cambridge University Press)

Moore. G. E. 1959. 'A Defence of Common Sense', Philosophical Papers (London: George Allen and Unwin)

Musgrave, Alan. 1993. Common Sense, Science and Scepticism: A Historical Introduction to the Theory of Knowledge (Cambridge: Cambridge University Press)

Peirce, Charles S. 1931-1958. Collected Papers, C. Hartshorne, P. Weiss and A. Burks, (eds.) (Cambridge, Massachusetts: Harvard University Press)

Reid, Thomas. 1983. Inquiry and Essays, ed. R. E. Beanblossom \& K. Lehrer (Indianapolis: Hacket)

Rescher, Nicholas. 2005. Common-Sense: A New Look at an Old Philosophical Tradition (Milwaukee: Marquette University Press) 